\title{
Impact of TNC on travel behavior and mode choice: a comparative analysis of Boston and Philadelphia
}

\author{
Xiaoxia Dong $^{1}$ (D) Erick Guerra $^{1}$ (D) $\cdot$ Ricardo A. Daziano $^{2}$ (D)
}

Accepted: 28 July 2021 / Published online: 9 August 2021

(C) The Author(s), under exclusive licence to Springer Science+Business Media, LLC, part of Springer Nature 2021

\begin{abstract}
We compare responses from an online survey among 700 customers of transportation network companies (TNC) in Boston and Philadelphia to investigate TNC's impact on vehicle ownership, trip making, and mode choice. We first use a qualitative comparative analysis to examine changes in respondents' travel behavior and vehicle ownership after adopting TNC. We then use a random parameter logit regression analysis to investigate customers' preferences between transit and TNC based on a choice experiment. We find that in both cities, TNC allows customers, including those who currently do not own a car, to either delay purchasing a car or forgo a car altogether. TNC enables customers across income levels to take trips that they otherwise would not have taken. Meanwhile, TNC substitutes for more than complementing transit. The random parameter logit analysis indicates that when choosing between TNC and transit, individuals in both cities consider waiting time and overall travel time for transit to be more burdensome than those for TNC. Bostonians perceive the time spent walking to and from transit to be less burdensome, and the time spent traveling in vehicle to be more burdensome than do Philadelphians. Differences in built environment, mode share within transit systems, and income likely contribute to respondents' different values of time between the two cities. Our paper is the first to compare individual trade-off between transit and TNC in two cities with different urban settings and transit services. The findings have implications on transit service planning, station area improvements, parking regulations, and traffic management.
\end{abstract}

Keywords Boston $\cdot$ Mixed logit $\cdot$ Philadelphia $\cdot$ Survey $\cdot$ TNC $\cdot$ Transit

Xiaoxia Dong

xiaoxiad@design.upenn.edu

Erick Guerra

erickg@upenn.edu

Ricardo A. Daziano

daziano@cornell.edu

1 Department of City and Regional Planning, University of Pennsylvania, Philadelphia, PA 19104-6311, USA

2 School of Civil and Environmental Engineering, Cornell University, Ithaca, NY 14853, USA 


\section{Introduction}

Since the early 2010s, on-demand, door-to-door ride-hailing services provided by transportation network companies (TNC) like Uber and Lyft have become a popular travel mode especially in large cities. In New York City, for example, TNC services completed 219 and 248 million revenue trips in 2018 and 2019, compared to 103 and 85 million trips completed by traditional Yellow taxis in the respective years (NYC Taxi \& Limousine Commission n.d. n.d.). Coinciding with the growth of TNC has been declines in transit ridership (American Public Transportation Association 2020). Before the COVID-19 pandemic disrupted travel, Philadelphia's bus ridership had decreased since 2014 and dropped to the lowest level since the Great Recession in 2019 (National Transit Database 2019). Several studies have also attributed worsening traffic conditions in downtown areas and increased vehicle miles traveled (VMT) at least in part to the increase in TNC use (Center City District 2018; Fehr and Peers 2019; Schaller 2018).

TNC's increasing presence has prompted scholars to investigate the service's impact on individual travel behavior and mode choice. However, findings are still inconclusive in several areas. For example, it is unclear how TNC in cities with a wide range of travel options affects vehicle ownership decisions for individuals with different vehicle ownership statuses. While recent evidence has pointed to TNC's substitution effect on transit, few studies have examined how individuals weigh travel options when choosing between transit and TNC services, and whether their choices are affected by different socio-economic characteristics, built environment, and transit service factors. For instance, individuals might consider walking to and from transit stations a lesser burden in more pedestrian friendly settings, and therefore might be more willing to choose transit over TNC services. Meanwhile, the time spent traveling in a TNC or a transit vehicle might be considered more "valuable" for residents in wealthier cities than those in less wealthy cities.

In this paper, we compare responses from an online survey among 421 and 294 TNC customers in Boston, Massachusetts, and Philadelphia, Pennsylvania, to investigate TNC's impact on individuals' vehicle ownership, trip making, and mode choice. Boston and Philadelphia are both older, large multimodal cities with relatively high transit share and dense urban environment. Meanwhile, there are notable differences between the cities in walking environment, transit service, and residents' socio-economic characteristics. These differences could contribute to different responses in travel behavior after adopting TNC services. They may also help explain the variations in TNC customers' preferences when choosing between transit and TNC. Understanding how individuals respond to TNC services in different urban settings helps bridge the gap in the TNC literature and informs decision making in land use and transit service adjustments in response to growth in TNC use.

Our study consists of a qualitative comparative analysis of the changes in surveyed TNC customers' travel behavior after adopting TNC and a random parameter logit regression analysis of their preferences between transit and TNC service. We find that by providing a convenient on-demand transport service, TNC allows customers to either delay purchasing a car or forgo a car altogether. The service also enables customers across all income levels to take trips, especially errand trips and trips for recreational and social purposes, that they otherwise would not have taken without the service. Meanwhile, by allowing more trips and by replacing trips that were previously taken by transit, walking, and biking, TNC likely increases vehicle miles traveled. Our random parameter logit regression analysis on the responses to a series of stated preference choice experiments shows that when choosing 
between TNC service and transit, individuals in both cities consider the overall travel time for transit to be more burdensome than that for TNC. Differences in built environment characteristics, mode share within transit systems, and income levels likely contribute to the different values of time for respondents between the two cities. Increasing TNC fares substantially or improving transit service could prompt TNC customers to switch to transit.

Our paper makes three primary contributions to the TNC literature. First, it provides further evidence on changes in individual travel behavior and vehicle ownership after adopting TNC services in two large, multimodal cities. Second, not only does the paper highlight TNC's substitution effect on transit and other transport modes, but it also examines the characteristics of the trips replaced. It thus sheds additional lights on TNC's impact on traditional travel modes. Last, to the authors' knowledge, this paper is the first to compare the trade-off between transit and TNC for individuals when making mode choice decisions in two cities with different urban settings and transit services. It provides further evidence on the importance of transit service improvements in retaining transit passengers or attracting TNC customers to transit. The findings have practical implications on transit service planning, station area improvements, parking regulations, and traffic management.

The remainder of the paper is organized as follows. We first examine previous studies on TNC's relationship with vehicle ownership, travel behavior, mode choice, and transit ridership, as well as policy responses to TNC's externalities. We then explain the study area, survey design, and survey distribution, followed by a discussion of key findings from the qualitative comparative analysis and the random parameter logit regression analysis. In the last section, we discuss our findings' implications on transit service planning, planning policies, and traffic management.

\section{Previous studies on TNC}

In several survey studies, scholars have explored TNC's impact on trip making, mode choice, and car ownership in U.S. cities. Overall, TNC services reduce personal driving for 30-70\% of survey respondents (Alemi et al. 2018; Clewlow and Mishra 2017; Tirachini 2020). Reduction in personal driving is bigger among frequent TNC users. More than half of those who use TNC services daily reported a reduction of 50 miles a week or more from driving (Clewlow and Mishra 2017). Across studies, between 12 and 40\% of TNC trips would have been completed by personal driving had TNC services not been available. The reduction in driving, however, may not translate to declines in vehicle mile traveled. A quasi-natural experiment indicates that TNC increases VMT by $84 \%$ over what would have been driven had TNC not existed (Henao and Marshall 2018). In addition to driving, research has shown that TNC replaces non-motorized modes such as walking and biking, and induces trips that would not have taken place at all had the service not been available (Clewlow and Mishra 2017; Feigon and Murphy 2016; Metropolitan Area Planning Council 2018; Rayle et al. 2016).

While car ownership is negatively related to TNC use in general (Conway et al. 2018; Smith 2016), changes in individual vehicle ownership after adopting TNC is less clear. Scholars suggest that TNC could increase vehicle ownership by motivating would-be TNC drivers to purchase new vehicles (Ward et al. 2021); decrease vehicle ownership by providing a travel alternative and allowing car owners to own fewer personal cars (Henao and Marshall 2018); or have no significant impact (Diao et al. 2021) on vehicle ownership. 
Several scholars have also studied TNC's pricing scheme, with particular attention to the service's dynamic, or surge pricing (see, for example (Wang and Yang 2019)). Scholars have also examined the effect of TNC's pricing scheme on the supply and demand of the service. For example, Chen (2016) finds that surge pricing significantly increases the supply of Uber rides (Chen 2016). Castillo (2020) finds that TNC customers' decisions to request a trip is very inelastic to real-time price changes (Castillo 2020). In the long run, customers' decisions to use the TNC app are more responsive to expected prices (Castillo 2020). TNC prices also affect customer behavior. The price multiplier used to calculate dynamic pricing, along with passengers' eagerness to request a ride under given circumstances, affects passengers' frequency of conducting fare estimations of intended trips on the TNC app in search for better fares (Guo et al. 2018).

Surveys and statistical analyses that investigate TNC's relationship with transit ridership have found inconsistent results. Some research indicates that TNC services could complement public transit by connecting transit stations to passengers' trip origins or destinations, and by filling service gaps due to low transit coverage or infrequent services (Feigon and Murphy 2016; Rayle et al. 2016). Meanwhile, TNCs could erode transit ridership by competing for transit's core demand (Rayle et al. 2016) and substituting for transit. In Clewlow and Mishra's survey study, $15 \%$ of the respondents would have taken transit had TNC not been available for the referenced trip (Clewlow and Mishra 2017). New York City's annual mobility report states that $50 \%$ of all ride-hailing app users replaced transit trips with for-hire vehicle services (NYC Department of Transportation 2018), the majority of which were provided by transportation network companies. Hall, Paladin and Price's difference-in-differences analysis finds that Uber complements transit and increases ridership more to small transit agencies and agencies in large cities (Hall et al. 2018). Boisjoly et al.'s multilevel longitudinal study indicates that TNC positively corresponds with transit ridership in 25 North American transit agencies, although the association is statistically insignificant (Boisjoly et al. 2018). Using more recent ridership data for 22 major North American cities, Graehler et al. conclude that TNC contributes to the recent ridership declines (Graehler et al. 2019). Gehrke et al. find that TNC services' substitution for transit corresponds to the built environment, accessibility to transit, and individuals' socio-economic status (Gehrke et al. 2019). Using TNC surge multiplier data, a study in Pittsburgh, Pennsylvania, finds that the interaction between TNC services and public transit changes by location and time of day (Grahn et al. 2020).

TNC's impact on vehicle ownership, mode choice, and travel behavior has prompted discussions on the regulatory and planning responses to the service. To internalize the externalities associated with increased travel by TNC such as congestion (Erhardt et al. 2019; Diao et al. 2021), cities have levied taxes on TNC fares (e.g., Philadelphia), placed flat fees on TNC trips (e.g., Chicago), or capped the number of TNC vehicle licenses (e.g., New York City). Scholars have argued that the substitution for private cars with TNC on driving trips reduces the demand for parking, which in turn frees up land for more desirable uses (Henao and Marshall 2019; Tirachini 2020). TNC's substitution for walk trips has prompted scholars to recommend a fare scheme that prices the first mile of the trips more heavily (Lavieri and Bhat 2019). Scholars have also reminded cities to pay particular attention to managing pick-up and drop-off space for TNC services (Henao and Marshall 2019). To provide first and last mile connections while reducing operating costs, several transit agencies have partnered with transportation network companies, although it is unclear whether these partnerships met transit agencies' goals and needs (Pike and Kazemian 2019). 
Overall, the review of literature reveals that while TNC replaces trips on other modes such as driving, walking, and transit, and likely increases travel, the service's impact on vehicle ownership, travel behavior, and mode choice across population with different socioeconomic statuses is inconclusive and merits further analysis.

\section{Study area and TNC customer survey}

\section{Study area}

Table 1 compares the geographic and socio-economic characteristics of Boston and Philadelphia. Both cities are older, multimodal cities in northeastern United States. In both cities, population densities and transit commute mode shares are higher than the national averages. Compared to residents of Philadelphia, Bostonians are wealthier, more educated, and rely more heavily on transit (U. S. Census Bureau 2019). Philadelphia is bigger, with a population more than doubling and a land area tripling Boston's. While the two cities have comparable overall population densities, Boston's built environment resembles the central part of Philadelphia, where dense, walkable, transit accessible neighborhoods support mixed land use. In Philadelphia, buses carried more than $50 \%$ of the total transit passenger trips in 2019 while the subway carried 30\% (Federal Transit Administration 2019). By contrast, Bostonians rely more on the subway, which carried more than $40 \%$ of all passenger trips, compared with 35\% on buses (Federal Transit Administration 2019). Affordable TNC services (i.e., the basic non-shared TNC options such as UberX, as opposed to the more expensive options such as UberXL) entered Boston and Philadelphia in 2013 and 2014 , respectively.

\section{Survey design and distribution}

The survey study consists of two separate online questionnaires for the cities of Boston and Philadelphia. The surveys were designed on Qualtrics' online survey platform and consist of both stated and revealed preference questions in five sections: current travel behavior (e.g., Rank your frequency of usage per week by each of the following modes.), changes in trip making and vehicle ownership after adopting TNC (e.g., Has adopting ride hail affected the number of trips you take for each of the following activities? Has adopting ride-hail allowed you and your household to make any of the following changes?),

Table 1 Comparison of geographic and socio-economic conditions between Boston and Philadelphia

\begin{tabular}{lll}
\hline & Boston & Philadelphia \\
\hline Population & 692,600 & $1,584,064$ \\
Land area (sq. mi.) & 48.3 & 134.1 \\
Population per sq. mi & $12,792.7$ & $11,379.5$ \\
Median age (years) & 32.2 & 34.7 \\
Median household income (dollars) & 71,115 & 45,927 \\
College degree or higher (percent) & 46.9 & 29.3 \\
Transit commuter (percent) & 32 & 25.5 \\
Affordable TNC launch year & 2013 & 2014 \\
\hline
\end{tabular}


characteristics of last TNC trip (e.g., What was the purpose for the last ride hail trip you took?), individual characteristics (e.g., Please select in what year you were born. What was your household income before tax last year?), and transit versus TNC choice experiments. All survey questions are multiple choices, with a few questions allowing write-in answers in addition to the options presented to the respondents. Survey responses can be found in the supplementary material to this paper.

In the choice experiments section, we asked the respondents to choose between transit and TNC services (i.e., ride hail service) based on a series of attributes for each travel mode, including the trip's monetary cost, travel time, $\mathrm{CO} 2$ emissions, and so on. Figure 1 shows an example of a choice experiment presented to the respondents. Each respondent was presented 12 choice experiments that were randomly chosen from a pool of 24 choice experiments with different combinations of attribute levels (i.e., the values that describe each attribute) under each mode. All choice experiments presume the generic travel scenario explained in Fig. 1. The attributes in the choice experiments, including trip monetary cost, trip time, number of transfers, etc., have proven to affect travel utility and individual mode choices in the transit and mode choice literature, as well as recent studies on TNCs (see for example Yang et al. 2009; Rayle et al. 2016; Guo and Wilson 2004; Liu et al. 1997).

Attribute levels in the choice experiment were calculated based on the 2017 National Household Travel Survey, the TNC literature, and reports from federal agencies and local transit operator. Using the 2017 NHTS, we calculated the attribute levels for the trip time components based on Philadelphia region's residents' median wait time for transit, walk time to access transit, median in-vehicle travel times for taxis (including TNC trips) and transit, and the number of transit transfers. Wait time for TNC was calculated based on the TNC literature (see, for example Brown 2018). We calculated trip costs for TNC using transportation network company's online price schedule. The calculation took into account trip duration and distance, which were estimated based on the median distance and time traveled by taxis in the Philadelphia region as reported by the NHTS. Transit fare levels were based on SEPTA's fare schedule in 2018. Carbon dioxide emissions for TNC came from the Federal Transit Administration's estimates for per passenger mile $\mathrm{CO}_{2}$ emission for single occupancy vehicles (Federal Transit Administration 2010). Transit emissions came from the emission profiles for SEPTA's various transit modes (Southeastern Pennsylvania Transportation Authority 2019). The combinations of attribute levels were

Imagine that you need to make a trip to return home. You do not have access to a car and the only available options are non-shared ride hail (e.g., UberX and Lyft) and transit. Please make your choice between ride hail and transit from the information below.

\begin{tabular}{|c|c|c|}
\hline & Ride hail & Transit \\
\hline Cost & $\$ 15$ & $\$ 1.5$ \\
\hline Wait time & 6 minutes & 12 minutes \\
\hline Travel time spent in vehicle & 30 minutes & 20 minutes \\
\hline Total walk time to and from transit stop/station & & 20 minutes \\
\hline Number of transfers & & One transfer to another line \\
\hline $\mathrm{CO}_{2}$ emissions per mile & 0.57 pounds & 0.6 pounds \\
\hline
\end{tabular}

Fig. 1 Example of a choice game presented to the respondents in the surveys 
generated using an efficient design in the Ngene survey design software. We direct the interested reader to a previous study using an expanded version of the Philadelphia survey for a detailed description of the attribute selection, attribute level calculation, and attribute level recalibration (Dong 2020). Attributes in the choice experiments are intended to examine how respondents value the various alternative specific factors when choosing between the two modes and may not reflect the actual transit and TNC fare structures and other trip characteristics in the study area.

The survey sample was purchased through Qualtrics. Instead of relying on a single panel of respondents, Qualtrics builds samples from multiple sources to form blended panels. Each sample from the panel base is proportioned to the general population (Qualtrics 2014). Respondents were compensated for answering the survey. The Boston survey includes only residents of Boston whereas the Philadelphia survey includes residents of the suburbs that are outside of the City of Philadelphia. To ensure the comparability between the samples from the two surveys, we excluded respondents who were not residents of Philadelphia in the Philadelphia survey. To be qualified for either survey, respondents must be over 18 years old at the time of the survey and had used TNC services. The Philadelphia survey was distributed to respondents in the Philadelphia region in four waves between March 18 and April 19, 2019. The first three waves were pre-tests and had 57, 43, and 50 complete responses, respectively. Based on results from the first and second waves, we adjusted the attribute levels for the choice experiments. The Boston survey was distributed in two waves between June 21, 2019 and July 8, 2019, with the first wave of 50 responses being the pre-test. In the Boston survey, we did not modify the survey after the first wave. The final dataset includes responses from all waves of survey responses from each city.

\section{Survey summary}

Table 2 compares the socio-economic characteristics of the survey sample in Boston and Philadelphia with those of the resident population in each city as reported by the 2019 American Community Survey 1-Year Estimates (U. S. Census Bureau 2019). Compared to the population in Boston and Philadelphia, the survey samples skew toward female, are younger, less wealthy, and better educated. In both cities, the percentages of white residents are bigger in the survey samples than in the resident populations. For Boston, household vehicle ownership status is similar between the sample and the resident population. The Philadelphia sample skews toward individuals with zero or only one vehicle. The socioeconomic characteristics of the populations of Boston and Philadelphia might not be representative of the TNC user population in each city. Due to the lack of data, we do not report the characteristics of the TNC customer populations in Boston and Philadelphia.

Survey respondents used TNC services infrequently and for short trips. The infrequent use of TNC services echoes findings from previous survey studies and indicates that TNC customers likely use the services to fill occasional rather than regular travel needs (see, for example Brown 2018). We convert the reported trip cost and wait time for respondents' last TNC trip into continuous values by using the mid-point of the ranges presented to the respondents in the survey. For example, a respondent who reported waiting 2-4 $\mathrm{min}$ for her/his TNC vehicle to arrive is counted as waiting for 3 min. Wait time above 10 times is considered to be 10 . On average, Bostonians' and Philadelphians' last TNC trips cost $\$ 11$ and \$10, respectively, including tips. In both cities, respondents' average wait time for TNC was 5 min. Recreation, commute, and 
Table 2 Comparison of' socio-economic characteristics between survey respondents and resident population in Boston and Philadelphia (in percent)

\begin{tabular}{|c|c|c|c|c|}
\hline Socio-economic characteristics & $\begin{array}{l}\text { Boston sample } \\
(n=421)\end{array}$ & $\begin{array}{l}\text { Boston popu- } \\
\text { lation }\end{array}$ & $\begin{array}{l}\text { Philadelphia } \\
\text { sample } \\
(n=294)\end{array}$ & $\begin{array}{l}\text { Phila- } \\
\text { delphia } \\
\text { population }\end{array}$ \\
\hline \multicolumn{5}{|l|}{ Age } \\
\hline $19-34$ & 61 & 35 & 54.8 & 26.2 \\
\hline $35-54$ & 29.2 & 23.4 & 31 & 24 \\
\hline $55-64$ & 6.2 & 10.1 & 9.5 & 11.5 \\
\hline 65 and older & 3.6 & 12.1 & 4.7 & 14 \\
\hline \multicolumn{5}{|l|}{ Gender } \\
\hline Female & 72.8 & 52.2 & 79.6 & 53.8 \\
\hline Male & 27.2 & 47.8 & 20.4 & 46.2 \\
\hline \multicolumn{5}{|l|}{ Household income } \\
\hline Less than $\$ 10,000$ & 9 & 9.8 & 9.5 & 12.2 \\
\hline$\$ 10,000$ to $\$ 49,999$ & 29.7 & 25.2 & 51.4 & 39.5 \\
\hline$\$ 50,000$ to $\$ 99,999$ & 37.1 & 23 & 25.9 & 27.1 \\
\hline$\$ 100,000$ to $\$ 149,999$ & 14.2 & 14.9 & 10.5 & 10.5 \\
\hline$\$ 150,000$ or more & 10 & 27.1 & 2.7 & 10.8 \\
\hline \multicolumn{5}{|l|}{ Race } \\
\hline White & 69.6 & 53.2 & 51 & 39 \\
\hline African American & 13.3 & 24.9 & 34.7 & 41.5 \\
\hline Asian & 7.1 & 9.7 & 3.7 & 7.6 \\
\hline Other (including prefer not to tell) & 10 & 12.2 & 10.6 & 11.9 \\
\hline \multicolumn{5}{|l|}{ Education attainment } \\
\hline High school graduate or less & 14.6 & 29.3 & 26.5 & 46.3 \\
\hline Some college & 27.3 & 23.8 & 27.9 & 24.4 \\
\hline Bachelor's degree or higher & 58.1 & 46.9 & 45.6 & 29.3 \\
\hline \multicolumn{5}{|l|}{ Household vehicle } \\
\hline 0 & 19 & 24.4 & 28.3 & 18.4 \\
\hline 1 & 39.9 & 38 & 48.6 & 40.2 \\
\hline 2 & 29.7 & 23.4 & 19.7 & 29.2 \\
\hline 3 or more & 11.4 & 14.2 & 3.4 & 12.3 \\
\hline
\end{tabular}

errand trips were the most common trip types, each making up roughly one quarter of the total TNC trips last taken by the respondents. In comparison, fewer than $6 \%$ of the respondents in each city used TNC services to access transit.

\section{Post-TNC changes in travel behavior}

In this section, we present findings on the changes that the survey respondents in Boston and Philadelphia made in vehicle ownership, trip making, and mode choices after adopting TNC services. 


\section{Changes in vehicle ownership}

In both Boston and Philadelphia, TNC allowed respondents with different vehicle ownership statuses to postpone buying a car or not own a car at all. The surveys ask respondents whether they have postponed buying or leasing a car, decided not to buy or lease a car, sold a car and did not replace it, or purchased or leased a car since adopting TNC. Among the $44.6 \%$ and $45.9 \%$ of respondents in Boston and Philadelphia who made car ownership choices after adopting TNC service, a respective 26.6 and $14.8 \%$ decided not to buy or lease a car while 43.5 and $40.7 \%$ postponed purchasing a car. Additionally, 14.1 and $15.6 \%$ sold a car and did not replace it. While only $15.8 \%$ of the respondents in Boston purchased a car after adopting TNC services, nearly $30 \%$ did so in Philadelphia. In Boston and Philadelphia, respondents from carless households made up 21.3 and $28.6 \%$ of those who made car ownership decisions after adopting TNC, and accounted for 24.4 and 33.8\% of those who postponed buying or decided not to buy a car at all. None of the carless respondents in Boston purchased a car after adopting TNC services while only 5\% did in Philadelphia. Changes in post-TNC car ownership also varied across income levels. In each city, roughly $60 \%$ of the respondents who postponed buying or forwent a car altogether had household incomes below the city's median income.

\section{Changes in trip making}

Changes in trip making after adopting TNC varied across trip purposes, with trips for recreation and social purposes seeing the biggest increases. The surveys ask respondents to identify whether adopting TNC services has affected the number of trips they take for commute, shopping and errands, transit connection, and recreation or social events. Figure 2 shows that in each city, roughly one third of the respondents either increased or reduced the numbers of commute trips after adopting TNC services. By contrast, half of the respondents in each city changed their number of recreation/social trips after adopting TNC. Among the additional trips made by respondents in each city after adopting TNC, approximately $40 \%$ were for recreation and social purposes, compared to $30 \%$ for errand trips and $20 \%$ for transit connection trips. The finding that TNC enables more recreation and social trips echoes previous findings indicating that recreation and social trips are the most common trip purposes for TNC services (Tirachini 2020). In Boston, almost
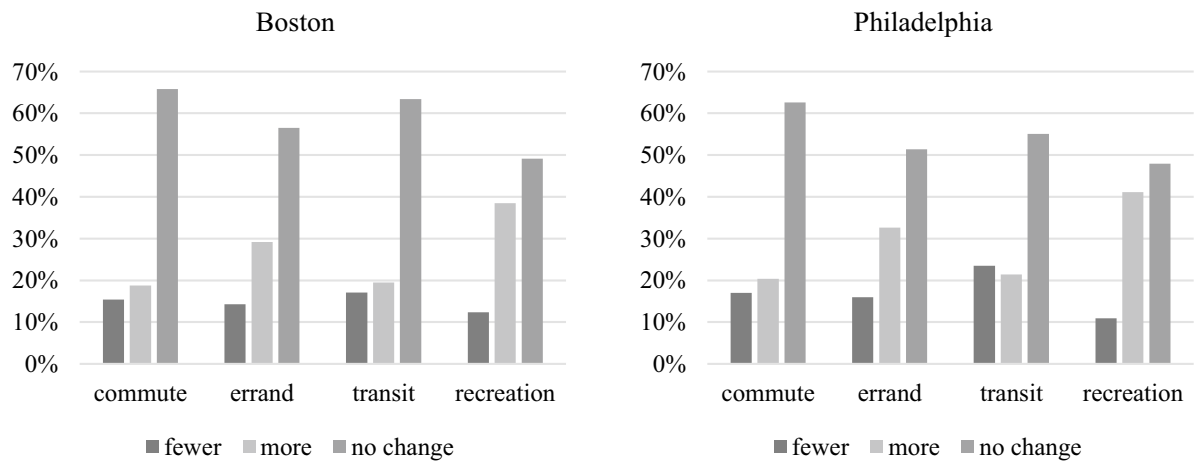

Fig. 2 Respondents' change in the numbers of trip by trip purpose after adopting TNC in Boston and Philadelphia 
an equal percentage of carless respondents took more trips for recreation purposes as did those who have at least one car after adopting TNC. Meanwhile, a greater percentage of carless respondents $(34.6 \%)$ took more errand trips than respondents with private vehicles $(27 \%)$. In Philadelphia, the percentage of carless respondents who took more recreation and errand trips is similar to that of car owners. In Boston and Philadelphia, 29.2 and $28.7 \%$ among those who did not own a car took more trips across trip purposes, compared to $25.5 \%$ and $28.5 \%$ among those who had at least one car.

Respondents' stated alternative for their last TNC trips offers additional insight into TNC's potential effect on trip making. In each city, 10-15\% of respondents across income levels that are below $\$ 100,000$ indicated that they would not have made their last trip at all if TNC services had not been available. Roughly $4 \%$ of Bostonians and $8 \%$ of Philadelphians making $\$ 100,000$ and above would not have taken the trip had TNC not been available. Around $40 \%$ of those respondents took their last TNC trip for recreation or social purposes, a greater percentage than the other trip purposes presented to respondents in the survey. In each city, more than $80 \%$ of the trips that would not have occurred without TNC took place either during off-peak periods on weekdays or on the weekend.

\section{Changes in mode choice}

In both cities, TNC services replaced transit more than it did other surveyed modes. When asked what mode the respondents would have taken had TNC services not been available for their last TNC trip, approximately $36 \%$ of respondents in each city answered transit. The substitution for transit is more pronounced among respondents without a car. In each city, approximately $53 \%$ of carless respondents replaced transit with TNC on their last TNC trip, compared to 30-33\% of car owning respondents. Consider that in each city, only 5-6\% of the respondents took their last TNC trip for transit connections, the results suggest that more TNC customers used the services to substitute for, rather than complementing public transit.

Service quality and safety were among the common concerns cited by respondents in both cities for choosing TNC over transit. For TNC customers who had the option to take transit on their last trip, a respective $53 \%$ and $42 \%$ chose TNC over transit in Boston and Philadelphia due to TNC's faster and better service. Concerns for safety varied across genders and age groups. Among female respondents in Boston and Philadelphia, 18\% and 10\% cited personal safety as one of their top reasons for favoring TNC over public transit on their last trip, compared to $14 \%$ and $5 \%$ among male respondents. The difference in safety concerns between female and male passengers echoes previous findings on perceptions of transit safety (Hsu et al. 2019; Namgung and Akar 2014).

In addition to replacing transit trips, TNC also substitutes for automobile trips and active transport modes such as biking and walking. Had TNC services not been available for their last trip, roughly $20 \%$ of the respondents in each city would have driven instead. In both cities, difficulty in finding parking (34\% for Boston and $29 \%$ for Philadelphia) and possible alcohol consumption (20\% for Boston and $18 \%$ for Philadelphia) were the most common factors that prompted respondents to choose TNC services over driving. In terms of active transportation, a respective $27 \%$ and $23 \%$ of the respondents in Boston and Philadelphia claimed to take fewer biking and walking trips after adopting TNC, while $15 \%$ and $31 \%$ of respondents biked and walked more. 


\section{Respondents' willingness to choose TNC over transit}

In this section, we compare respondents' willingness to choose TNC services over transit in Boston and Philadelphia based on their responses to the stated preference choice experiments. The final dataset excludes respondents who did not report their gender. For respondents who refused to report income, we impute their income using the median income of the respondents' home city.

\section{Random parameter logit modeling frame, model specification, and output interpretation}

We model respondents' choice between TNC and transit using a random parameter logit regression model. The random parameter logit or mixed logit model is an extension of the multinomial logistic regression (Sarrias and Daziano 2017), where the index function is seen as utility or satisfaction from consumption and where preference parameters are random. The following equation shows the basic form of the mixed logit model.

$$
U_{n i}=\beta_{n} X_{n i}+\varepsilon_{n i}
$$

where $\mathrm{U}_{\mathrm{ni}}$ is the utility for a given person $n$ and alternative $i$. The $\mathrm{X}_{n i}$ represents explanatory variables. The $\varepsilon_{n i}$ represents the error term assumed to be independent and identically distributed (iid) extreme value. The $\beta_{n}$ term represents the coefficients for the explanatory variables. Mixed logit allows the coefficient $\beta$ to vary randomly following certain distribution over decision makers in the population to reflect the different tastes across people. The varying $\beta$ over decision makers is the major difference between mixed logit and standard logit, whose $\beta$ 's are assumed to be fixed. Chapter 6 in Train (2009) describes the model specification and estimation procedure of mixed logit in greater detail (Train 2009). The random parameter logit model can approximate any random utility maximization model (McFadden and Train 2000) while not exhibiting the independence of irrelevant alternatives (IIA) property encountered in the standard conditional logit model (Sarrias and Daziano 2017). Furthermore, the inclusion of parameters that vary randomly across individuals (Train 2009) recovers unobserved differences in individual values or tastes.

Table 3 presents the parameter estimates from the random parameter logit models for Boston and Philadelphia. Both models include travel alternative specific characteristics associated with each mode, such as trip fares, wait time, and in-vehicle travel time. Previous TNC studies have found that TNC adoption and usage vary across individuals with different socio-economic backgrounds. To account for the potential associations between respondents' socio-economic characteristics and their preferences for TNC and transit, both models include individual characteristics such as income, age, and transit usage frequency. Trip monetary cost and in-vehicle travel time are disutility that likely have consistent negative signs across all respondents. In both models, we allow the parameter estimates for trip cost and in-vehicle travel time to vary randomly across individuals following log normal distribution to restrict the variables' directions of association with mode choice. We also tested models with the parameter estimate for in-vehicle travel time following normal distribution and triangular distribution. The results did not change the outcomes significantly and therefore are not reported. The well-documented health benefits of walking suggest that some respondents may consider the time spent walking to and from transit a benefit rather than a disutility. To reflect the potentially 
Table 3 Random parameter logit estimates for choice experiments for Boston and Philadelphia

\begin{tabular}{|c|c|c|}
\hline & \multicolumn{2}{|l|}{ Point estimate (SE) } \\
\hline & Boston (Model 1) & Philadelphia (Model 2) \\
\hline Intercept (TNC specific) & $-3.754 * * *(0.875)$ & $-2.348 *(1.032)$ \\
\hline Cost & $-2.495 * * *(0.133)$ & $-2.804 * * *(0.219)$ \\
\hline Walk time & $-0.045 * * *(0.010)$ & $-0.045 * * *(0.011)$ \\
\hline In-vehicle travel time & $-3.298 * * *(0.092)$ & $-4.037 * * *(0.190)$ \\
\hline \multicolumn{3}{|l|}{ Wait time } \\
\hline TNC & $-0.022(0.021)$ & $-0.011(0.024)$ \\
\hline Transit & $-0.042 * * *(0.010)$ & $-0.045 * * *(0.013)$ \\
\hline Transfer & $-0.307 * * *(0.087)$ & $-0.427 * * *(0.101)$ \\
\hline Gender $($ Reference $=$ Male $)($ TNC specific $)$ & $0.046(0.200)$ & $0.350(0.272)$ \\
\hline \multicolumn{3}{|l|}{$\begin{array}{l}\text { Income }(\text { Reference }=<\$ 30,000)(\mathrm{TNC} \\
\text { specific) }\end{array}$} \\
\hline$\$ 30,000$ to $\$ 50,000$ & $-0.102(0.289)$ & $0.177(0.261)$ \\
\hline$\$ 50,000$ to $\$ 70,000$ & $-0.096(0.261)$ & $0.179(0.308)$ \\
\hline$\$ 70,000$ to $\$ 100,000$ & $-0.075(0.302)$ & $0.234(0.373)$ \\
\hline$\$ 100,000$ to $\$ 150,000$ & $0.143(0.318)$ & $1.152 * *(0.379)$ \\
\hline$\$ 150,000$ or more & $0.295(0.339)$ & $1.518 *(0.718)$ \\
\hline Age (TNC specific) & $0.180 * * *(0.045)$ & $0.037(0.052)$ \\
\hline $\operatorname{Age}^{2}$ (TNC specific) & $-0.002 * * *(0.001)$ & $0.000(0.001)$ \\
\hline \multicolumn{3}{|l|}{$\begin{array}{l}\text { Transit usage (Reference }=\text { Average })(\mathrm{TNC} \\
\text { specific) }\end{array}$} \\
\hline Above average & $-0.193(0.216)$ & $0.101(0.245)$ \\
\hline Below average & $0.920 * * *(0.222)$ & $1.285 * * *(0.263)$ \\
\hline \multicolumn{3}{|l|}{ Standard deviation } \\
\hline Walk time & $0.084 * * *(0.009)$ & $0.071 * * *(0.009)$ \\
\hline In-vehicle travel time & $1.015 * * *(0.090)$ & $1.348 * * *(0.142)$ \\
\hline Log likelihood & -2556.9 & -1794.9 \\
\hline AIC & 5153.7 & 3629.8 \\
\hline $\mathrm{BIC}$ & 5284.2 & 3752.5 \\
\hline
\end{tabular}

Significance levels for a two-tail $z$-test: $* * * *<0.001, * *<0.01, *<0.05 *$

varying tastes on walking across respondents, we allow the parameter estimates for walk time to and from transit to vary following normal distribution. Since respondents might consider the time costs of waiting for TNC and transit vehicles to arrive to be different, we allow the parameter estimate for wait time to be different between transit and TNC to capture the potential difference in the disutility of waiting between the two modes. Vehicle ownership is likely correlated with income and is therefore excluded from the reported models. The $\mathrm{CO}_{2}$ emission profiles were considered to be the least important factor by the majority of respondents when choosing between TNC and transit and are therefore excluded from the models. We model the responses as panels to account for correlation across repeated choices from each respondent (Guerra 2019). The reported models use 1000 draws, Halton sequences in the estimation. Overall, respondents chose TNC and transit 2832 and 2196 times in Boston, and 1814 and 1606 times in 
Philadelphia. Random parameter logit models are estimated using the mlogit package (Croissant 2019) and the gmnl package (Sarrias and Daziano 2017) in the R software.

We convert transit usage frequency into a continuous variable by using the mid-point method explained in the Survey summary section. We impute the incomes of the 36 respondents in Boston and 21 in Philadelphia who preferred not to disclose their incomes by using the median household income for each city from the 2019 American Community Survey 5-year estimate. Income is regrouped into six categories, with the income below $\$ 30,000$ being the reference category in the models. The age variable is a continuous variable that represents respondents' age as of 2019. Those who were older than 65 years old are considered to be 65 years old in the analysis. We include a quadradic term for the age variable to capture the potential non-linear relationship between individuals' age and willingness to choose TNC service over transit.

Coefficient estimates are interpreted as marginal utility. For example, Model 1 indicates that each additional minute spent walking to and from transit is associated with a 0.045 unit of disutility for an average respondent in the Boston survey, all else being equal. Exponentiated coefficients have the interpretation as odds ratios. For example, in Model 1, an additional transfer from one transit line to another corresponds with $26.4 \%$ lower odds of choosing transit, all else being equal. Coefficients for the log normally distributed in-vehicle travel time and trip monetary cost variables can be calculated from the point estimates for the means $(m)$ and the standard deviations $(s)$ of the variables using $\exp \left(m+\left(s^{2} / 2\right)\right)$ (Train 2009). The ratios between the point estimates for the alternative specific variables, such as wait time and in-vehicle travel time, and the point estimate for the monetary cost of trip have the interpretation as the monetary equivalent, or cost, of the alternative specific variable. For variables with random parameters (i.e., trip cost, in-vehicle travel time, and walk time), we simulate the point estimates by taking 10,000 random draws from the distributions of the random parameters. We then calculate the median of the ratios between the alternative specific variable and cost to derive the variable's monetary equivalent. In both models, transit is set as the reference or baseline choice.

\section{Cost of time}

Respondents in each city valued the different time components within a trip differently. On average, respondents valued an hour of in-vehicle travel time for transit and TNC to be equivalent to \$26 in Boston and \$18 in Philadelphia. The higher value of time for respondents in Boston likely reflects their higher incomes compared to respondents in Philadelphia. For reference, the median hourly wages calculated from respondents' reported income are approximately \$28 in Boston and \$23 in Philadelphia. Every 15 min spent walking to and from a transit station/stop has an average equivalent monetary cost of less than $\$ 6$ in Boston and \$7 in Philadelphia, all else being equal. It should be pointed out that both the Boston and Philadelphia surveys were conducted in spring and summer months. Respondents' value for walking to and from transit and waiting for transit and TNC vehicles to arrive might be different in the cold winter months of the American Northeast.

In both cities, respondents considered waiting for transit to be more burdensome than waiting for TNC vehicles. On average, waiting $10 \mathrm{~min}$ for transit has the respective monetary equivalent of $\$ 5$ in Boston and almost $\$ 8$ in Philadelphia, compared to less than $\$ 3$ and $\$ 2$ for a 10 -min wait for TNC vehicles in each city. For reference, in a nationwide natural field experiment study using Lyft data, researchers find the value of time to be $\$ 19$ per h (i.e., $\$ 3.2$ per $10 \mathrm{~min}$ ), or $75 \%$ of after-tax mean wage rate. That study assumes the value 
of wait time to be the same as the value of in-vehicle travel time (Goldszmidt et al. 2020). The difference in the values of wait time between the two modes in each city likely reflects the different settings in which passengers waited for their transit or TNC vehicle to arrive. Thanks to its door-to-door, on demand service, TNC allows customers to wait in comfortable settings such as home and the office, as opposed to at bus stops or train stations for transit passengers. The higher level of discomfort associated with waiting for transit increases transit passengers' disutility, or cost, of waiting. In reality, the difference in the cost of waiting between transit and TNC services could be further exacerbated by transit's longer wait time than TNC. In the survey sample, TNC customers in both cities waited an average 5 min for their vehicle to arrive. Even in cities like Boston and Philadelphia, where transit runs frequently especially during peak periods, the typical headway is almost certainly longer than the average wait time for TNC. Differences in mode share within the transit systems in Boston and Philadelphia likely contribute to the different values of wait time for transit between the two cities. Unlike Philadelphia, where the majority of transit trips are carried by buses, Boston relies more on its subway system. Compared to bus stops, subway stations often have better facilities and provide better protection from the elements, thus reducing passengers' burden for waiting. In both cities, respondents consider the time spent waiting for transit to be more burdensome than those spent traveling in vehicle and walking to and from transit.

\section{Transfer penalty}

While respondents in both cities considered transfer between transit lines to be a significant disutility, respondents in Boston viewed transfers to be less burdensome than did respondents in Philadelphia. Compared to a trip with no transfer, a transit trip with one transfer lowers the odds of choosing transit by $26 \%$ in Boston and $35 \%$ in Philadelphia, all else being equal. For Bostonians, a transfer has the equivalent cost of roughly 9 min of travel time in a transit vehicle, compared to $20 \mathrm{~min}$ for Philadelphians. Although the surveys did not specify the type of transit services involved in the transfer, Boston's heavier reliance on rail transit likely reduces transfer penalty, as passengers consider rail to rail transfers to be less burdensome than transfers that involve buses (Taylor et al. 2009).

\section{Socio-economic characteristics and mode choice}

In both Boston and Philadelphia, respondents' frequency of transit use is significantly associated with their likelihood of choosing TNC over transit. Compared to the average transit usage frequency in each sample, respondents who used transit less often had 1.5-2.6 times higher odds of choosing TNC services over transit in Boston and Philadelphia. The models for both cities find no significant associations between respondents with above average transit usage and the willingness to choose TNC over transit.

Consistent with the TNC literature, respondents with higher incomes were more willing to choose TNC services over transit than respondents with lower incomes. In Philadelphia, willingness to choose TNC over transit increases with income level, with those making more than $\$ 100,000$ being the most willing TNC users. In Boston, while the highest income brackets correspond with higher willingness to choose TNC over transit, the association is not statistically significant. While individuals with higher incomes were more willing to choose TNC over transit in the choice experiments, the actual reported TNC usage frequency among respondents making more than $\$ 100,000$ in annual income is 
among the lowest in both cities. The lower actual TNC usage frequency among individuals with higher incomes is likely the result of wealthier respondents' better access to private vehicles. Among respondents with incomes above the median income of the respective city, $8 \%$ in Boston and $18 \%$ in Philadelphia did not own a car at the time of the survey.

We also find non-linear, significant associations between respondents' age and the willingness to choose TNC over transit among Bostonians. For respondents under 45 years old, the willingness to choose TNC over transit increases with age. Over 45, respondents' willingness to choose TNC decreases with age. The association between age and mode preferences is not statistically significant among respondents in the Philadelphia survey.

\section{Conditional parameters at the individual level}

We calculate the conditional means for each individual for in-vehicle travel time and the time spent walking to and from transit stop/station. Conditional means allow us to evaluate where in the distribution of taste, or value, of in-vehicle travel time and walk time each survey respondent lies in each city (Train 2009). Figure 3 shows the distributions of individual conditional means for in-vehicle travel time and walk time for respondents in Boston and Philadelphia. While on average respondents considered the time spent walking to and from transit to be a significant burden, 26-29\% of the respondents in each city valued walking positively, as indicated by the areas that are above zero in the right plot in Fig. 3.

\section{Implications on land use, transit service adjustments and traffic management}

We structure our discussion on the study's policy implications around four key findings. The first implication relates to transit ridership retainment and service adjustments. The finding that a significant proportion of TNC customers replaced transit with TNC services adds further evidence that TNC substitutes for more than complementing traditional transit. One way to encourage TNC customers to switch to transit is through fare increases for TNC services. In Boston, $46 \%$ of the respondents indicated that the monetary cost of trip was the most important factor when deciding between transit and
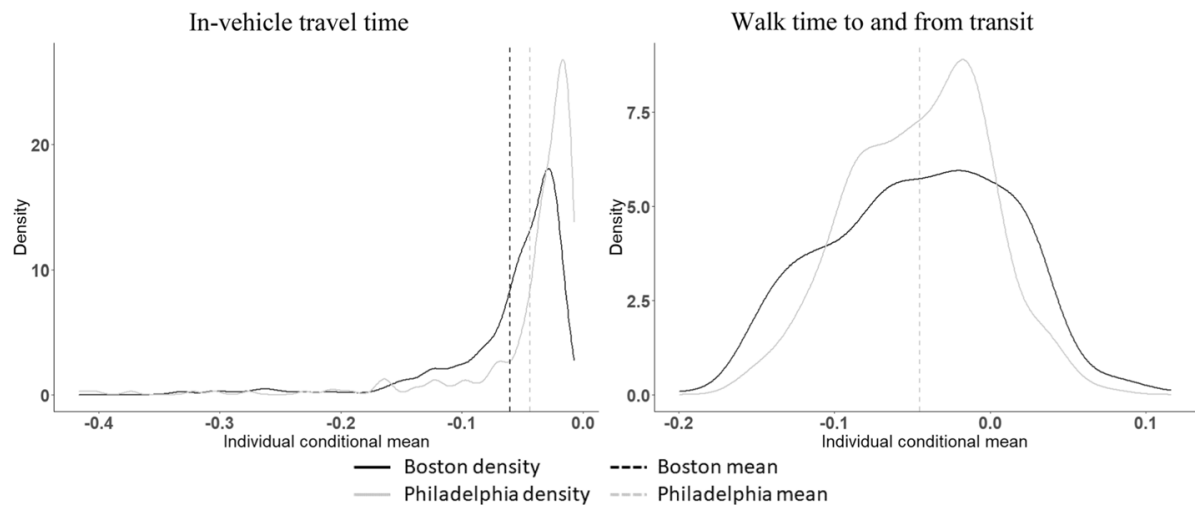

Fig. 3 Distributions of individual conditional means for in-vehicle travel time and walk time to and from transit in Boston and Philadelphia 
TNC in the choice experiments. Based on simulation from the random parameter logit models, a $20 \%$ increase in TNC fares results in 3-4\% higher mode choice for transit in both cities, while doubling TNC fares leads to $12-15 \%$ higher mode choice for transit. Meanwhile, since transit is already significantly cheaper than TNC services in both cities (e.g., a single trip on Massachusetts Bay Transportation Authority's subway and bus costs $\$ 2.4$ and $\$ 1.7$, compared to $\$ 11$ for an average TNC ride in the Boston sample), lowering transit fares further might not generate meaningful mode shift. While TNC fares might eventually increase as transportation network companies become less reliant on subsidies, in the short term, improving transit service continues to be a more viable option to retain transit riders or even attract TNC customers to transit. After all, among those who replaced transit with TNC on their last trip in each city, approximately half would have taken transit had it had better service, while fewer than $15 \%$ would not take transit under any circumstances.

In the meantime, TNC's substitution for transit reminds transit agencies to consider prioritizing transit services that could compete against TNC without dramatic increases in service frequency. Among respondents in both cities who could have taken transit on their last trip but chose TNC instead, nearly one third took the trip between $7 \mathrm{pm}$ and $7 \mathrm{am}$, when transit tends to operate less frequently. Almost $80 \%$ and more than $90 \%$ of the respondents in Boston and Philadelphia who took TNC during this period waited less than 10 min for their vehicle to arrive, with an average wait time of less than 6 min. Between 10 am and $4 \mathrm{pm}$, the period with the highest transit substitution by TNC in the samples, respondents in Boston and Philadelphia waited an average five and a half minutes and 5 min for their TNC vehicles to arrive. Making transit competitive to TNC in these off-peak hours likely requires dramatic increases in service frequency, which will place a significant financial burden on transit agencies due to the low transit demand and farebox revenue during these periods. Anticipating budget shortfalls in the wake of the COVID-19 pandemic, transit agencies that aim to rebound from the current ridership slumps should consider prioritizing service improvements that shorten travel time during periods of a day when transit could become competitive against TNC without significant increases in service frequency.

The second implication centers on the walking environment around transit stations/ stops. Respondents in Boston considered walking to and from transit to be less burdensome than their counterparts in Philadelphia, even though Bostonians' expected value of time is higher due to their higher income. While Boston and Philadelphia are both older cities with higher population density, Boston's built environment resembles the dense, walkable neighborhoods that are connected by a gridded street network in the central part of Philadelphia. Additionally, Boston's streets are safer for pedestrians, evident by the city's lower pedestrian fatality rate (1.61 fatalities per 100,000 population) compared to Philadelphia's (2.34 fatalities per 100,000 population). The better walking experience in transit station areas of Boston might help offset the expected higher time cost of walking to and from transit. The difference in the cost of walking across two cities with different walking environment highlights the importance of safe, pedestrian friendly station areas in reducing transit passengers' travel burden and enhancing transit's attractiveness against TNC services.

The third implication relates to TNC's impact on parking. Consistent with previous findings, our study provides further evidence that TNC enables both car owners and carless residents to postpone purchasing or even forgo a car altogether without reducing travel. By allowing residents to own fewer cars, TNC offers opportunities for cities to lower minimum parking requirements or expand reduced minimum parking requirements to more neighborhoods, especially neighborhoods that are served by other travel options such as transit. 
TNC also reduces demand for parking by allowing residents to drive less. In Boston, where both on- and off-street parking is scarce, one third of the survey respondents replaced driving with TNC on their last trip due to difficulty in finding parking.

The fourth and last implication focuses on traffic management due to the potential increases in vehicle miles traveled from TNC services. While most of the surveyed customers in each city did not change their trip making after adopting TNC services, a greater percentage of the respondents took more trips than those who took fewer trips for commute, errand, and recreation purposes. Additionally, 10-12\% of the respondents in each city would not have made their last trip had TNC not been available. The surveys also find a noticeable shift from transit, walking, and biking to TNC. The increased TNC use and TNC's substitution for transit and active transportation modes likely contribute to higher vehicle miles traveled. Even for trips that were previously made by private automobile, a shift to TNC almost certainly generates higher VMT due to the additional distance traveled by TNC vehicles to pick up passengers. On the one hand, the increased travel indicates that TNC provides a travel alternative for people, including lower-income, carless residents, who previously lacked access. In each city, TNC enabled almost one third of the survey respondents who did not have a car to take more trips. On the other hand, increased automobile trips present challenges to traffic management for local transportation authorities. Several cities, including Philadelphia, have reported worsening congestion and curb conditions in downtown (Center City District 2018; Fehr and Peers 2019). Identifying spatial and temporal TNC hotspots using TNC trip data could help cities implement targeted strategies to mitigate congestion. Cities like New York and Chicago have shown the feasibility for transportation network companies to publish anonymized TNC trip data without compromising user privacy.

\section{Conclusion}

In this paper, we analyze responses from two surveys among more than 700 TNC customers in Boston and Philadelphia to investigate TNC's impact on travel behavior and mode choice, as well as travel mode related factors and built environment characteristics that affect individual preferences between TNC and transit. We find that adopting TNC allowed respondents, including those who currently do not own a car, to delay purchasing a car or forgo a car altogether. TNC also enabled respondents, including lower-income respondents, to make trips that they otherwise would not have made, even though most respondents did not change their overall number of trips after adopting TNC. Among the previous travel modes that were replaced by TNC, transit is the most common. This finding provides further evidence on TNC's substitution effect on transit. Respondents who favored TNC services over transit considered the former's shorter overall travel time to be an important factor. Socio-economic characteristics, station area walking environment, and mode share within transit system likely contribute to the differences in individual preferences for TNC and transit between the two cities. Simulation based on our random parameter logit model indicates that raising TNC fares significantly could prompt a sizable portion of TNC customers to switch to transit. Before transportation network companies increase their services' fares, however, it is crucial for transit agencies to improve transit services in targeted areas and time of day that allow transit to compete against TNC.

The current analysis has three major limitations. First, while Qualtrics uses several sampling measures to ensure the quality of the sample, the lack of information on the TNC user 
population presents a challenge to select a representative sample. The online survey format could also introduce sample bias to the data. Second, the choice games present a generic travel scenario to all respondents. In reality, the cost of travel for the same individual could vary by factors such as trip purpose, time of day of travel, conditions of transit station/stop, weather, and so on. For example, walking to and waiting at a transit station is likely to be more burdensome on a snowy night in December than on a sunny morning in June. Last, while several questions are intended to investigate changes in respondents' travel behavior and mode choice as a result of adopting TNC services, such changes are often simultaneously affected by other factors such as changing home or work locations and changing income. Thus, the relationship between using TNC services and changing travel behavior and mode choice may not be interpreted as causal.

Supplementary Information The online version contains supplementary material available at https://doi. org/10.1007/s11116-021-10220-5.

Acknowledgements Funding support was provided by the U.S. Department of Transportation (USDOT) Tier 1 University Transportation Center "Cooperative Mobility for Competitive Megaregions" (CM2; USDOT Award No. 69A3551747135). The survey study was supported by a research grant from the Kleinman Center for Energy Policy at the University of Pennsylvania Stuart Weitzman School of Design.

Author Contributions All authors contributed to the study conception, design, data collection, statistical analysis, and manuscript preparation. All authors read and approved the final manuscript.

Funding Funding support was provided by the U.S. Department of Transportation (USDOT) Tier 1 University Transportation Center "Cooperative Mobility for Competitive Megaregions" (CM2; USDOT Award No. 69A3551747135). The survey study was supported by a research grant from the Kleinman Center for Energy Policy at the University of Pennsylvania Stuart Weitzman School of Design.

Availability of data and material Survey responses are available upon request.

Code availability $\mathrm{R}$ code for statistical models is available upon request.

\section{Declarations}

Conflicts of interest The authors have no conflicts of interest to declare.

Ethical approval The survey study was approved by University of Pennsylvania's Institutional Review Board.

Consent for publication All authors agreed with the content and all gave explicit consent to submit.

\section{References}

Alemi, F., Circella, G., Handy, S., Mokhtarian, P.: What influences travelers to use Uber? Exploring the factors affecting the adoption of on-demand ride services in California. Travel Behaviour and Society 13(October), 88-104 (2018). https://doi.org/10.1016/j.tbs.2018.06.002

American Public Transportation Association. "2020 Public Transportation Fact Book." American Public Transportation Association (2020). https://www.apta.com/wp-content/uploads/APTA-2020-FactBook.pdf.

Boisjoly, G., Grisé, E., Maguire, M., Veillette, M.-P., Deboosere, R., Berrebi, E., El-Geneidy, A.: Invest in the ride: A 14 year longitudinal analysis of the determinants of public transport ridership in 25 North American Cities. Transp. Res. A Policy Practice 116(October), 434-445 (2018). https://doi.org/10. 1016/j.tra.2018.07.005

Brown, Anne. Ridehail Revolution: Ridehail Travel and Equity in Los Angeles. UCLA (2018). https://escho larship.org/uc/item/4r22m57k. 
Castillo, Juan Camilo. Who Benefits from Surge Pricing?" SSRN Scholarly Paper ID 3245533. Rochester, NY: Social Science Research Network (2018). https://papers.ssrn.com/abstract=3245533.

Center City District. Keep Philadelphia Moving. February 28, 2018. http://centercityphila.org//researchreports/2018congestion (2018).

Chen, M. Keith. Dynamic Pricing in a Labor Market: Surge Pricing and Flexible Work on the Uber Platform. In: Proceedings of the 2016 ACM Conference on Economics and Computation, 455. EC '16. New York, NY, USA: Association for Computing Machinery (2016). https://doi.org/10.1145/29407 16.2940798.

Clewlow, Regina R., Gouri Shankar Mishra. Disruptive Transportation: The Adoption, Utilization, and Impacts of Ride-Hailing in the United States. Davis, CA: University of California, Davis (2017). https://trid.trb.org/view/1485471.

Conway, M.W., Salon, D., King, D.: Trends in taxi use and the advent of ridehailing, 1995-2017: Evidence from the US National Household Travel Survey. Urban Science 2(3), 79 (2018). https://doi. org/10.3390/urbansci2030079

Croissant, Yves. Mlogit: Multinomial Logit Models (version 1.0-1) (2019). https:/CRAN.R-project.org/ package $=$ mlogit.

Diao, Mi, Hui Kong, Jinhua Zhao. Impacts of transportation network companies on urban mobility. Nature Sustainability (2021). https://doi.org/10.1038/s41893-020-00678-Z.

Dong, X.: Trade Uber for the bus? J. Am. Plann. Assoc. 86(2), 222-235 (2020). https://doi.org/10.1080/ 01944363.2019.1687318

Erhardt, Gregory D., Sneha Roy, Drew Cooper, Bhargava Sana, Mei Chen, Joe Castiglione. Do transportation network companies decrease or increase congestion? Science Advances 5(5), eaau2670 (2019). https://doi.org/10.1126/sciadv.aau2670.

Federal Transit Administration. Public Transportation's Role in Responding to Climate Change. (2010) https://www.transit.dot.gov/sites/fta.dot.gov/files/docs/PublicTransportationsRoleInRespondi ngToClimateChange2010.pdf.

Federal Transit Administration. Monthly module adjusted data release. Text. Federal Transit Administration. (2019). https://www.transit.dot.gov/ntd/ntd-data.

Fehr, Peers. Estimated TNC Share of VMT in Six US Metropolitan Regions. (2019) https://www.fehra ndpeers.com/what-are-tncs-share-of-vmt/.

Feigon, Sharon, Colin Murphy. Shared mobility and the transformation of public transit. Washington, DC: The National Academies Press (2016). https://www.nap.edu/catalog/23578/shared-mobilityand-the-transformation-of-public-transit.

Gehrke, S.R., Felix, A., Reardon, T.G.: Substitution of ride-hailing services for more sustainable travel options in the Greater Boston Region. Transp. Res. Rec. 2673(1), 438-446 (2019). https://doi.org/ 10.1177/0361198118821903

Goldszmidt, Ariel, John List, Robert Metcalfe, Ian Muir, V. Kerry Smith, Jenny Wang. The Value of Time in the United States: Estimates from Nationwide Natural Field Experiments. w28208. Cambridge, MA: National Bureau of Economic Research (2020). https://doi.org/10.3386/w28208.

Graehler, Michael, Alex Mucci, Gregory Erhardt. Understanding the recent transit ridership decline in major US Cities: Service Cuts or Emerging Modes? (2019)

Grahn, R., Sean Qian, H., Matthews, S., Hendrickson, C.: Are travelers substituting between Transportation Network Companies (TNC) and public buses? A case study in Pittsburgh. Transportation (2020). https://doi.org/10.1007/s11116-020-10081-4

Guerra, E.: Electric Vehicles, Air Pollution, and the Motorcycle City: A Stated Preference Survey of Consumers' Willingness to Adopt Electric Motorcycles in Solo, Indonesia. Transportation Research Part D: Transport and Environment, Urbanization, Transportation and Air Quality in Developing Countries 68(March), 52-64 (2019). https://doi.org/10.1016/j.trd.2017.07.027

Guo, Suiming, Chao Chen, Yaxiao Liu, Ke Xu, Dah Ming Chiu. Modelling passengers' reaction to dynamic prices in ride-on-demand services: a search for the best fare. In: Proceedings of the ACM on Interactive, Mobile, Wearable and Ubiquitous Technologies 1(4), 136:1-136:23. https://doi.org/ $10.1145 / 3161194$.

Guo, Z., Wilson, N.H.M.: Assessment of the transfer penalty for transit trips geographic information system-based disaggregate modeling approach. Transp. Res. Rec. 1872(1), 10-18 (2004). https:// doi.org/10.3141/1872-02

Hall, J.D., Palsson, C., Price, J.: Is Uber a substitute or complement for public transit? J. Urban Econ. 108(November), 36-50 (2018). https://doi.org/10.1016/j.jue.2018.09.003

Henao, A., Marshall, W.E.: The impact of ride-hailing on vehicle miles traveled. Transportation, September. (2018). https://doi.org/10.1007/s11116-018-9923-2 
Henao, A, Marshall, W.E.: The impact of ride hailing on parking (and Vice Versa). J. Transport Land Use 12 (1) (2018). https://doi.org/10.5198/jtlu.2019.1392.

Hsu, H.-P., Boarnet, M.G., Houston, D.: Gender and rail transit use: influence of environmental beliefs and safety concerns. Transp. Res. Rec. 2673(4), 327-338 (2019). https://doi.org/10.1177/0361198119 837193

Lavieri, P.S., Bhat, C.R.: Investigating objective and subjective factors influencing the adoption, frequency, and characteristics of ride-hailing trips. Transp. Res. C: Emerging Technol. 105(August), 100-125 (2019). https://doi.org/10.1016/j.trc.2019.05.037

Liu, R., Pendyala, R.M., Polzin, S.: Assessment of intermodal transfer penalties using stated preference data. Transp. Res. Rec. 1607(1), 74-80 (1997). https://doi.org/10.3141/1607-11

McFadden, D., Train, K.: Mixed MNL models for discrete response. J. Appl. Economet. 15(5), 447-470 (2000). https://doi.org/10.1002/1099-1255(200009/10)15:5\%3c447::AID-JAE570\%3e3.0.CO;2-1

Metropolitan Area Planning Council. Fare choices: a survey of ride-hailing passengers in Metro Boston. (2018). https://www.mapc.org/farechoices/.

Namgung, Mi., Akar, G.: Role of gender and attitudes on public transportation use. Transp. Res. Rec. 2415(1), 136-144 (2014). https://doi.org/10.3141/2415-15

National Transit Database. Monthly Module Adjusted Data Release. Text. Federal Transit Administration. (2019). https://www.transit.dot.gov/ntd/data-product/monthly-module-adjusted-data-release.

NYC Department of Transportation. New York City Mobility Report. NYC Department of Transportation (2018). http://www.nyc.gov/html/dot/downloads/pdf/mobility-report-2018-print.pdf.

Pike, Susan, Sara Kazemian. Partnerships between ridehailing companies and public transit agencies: An exploration of inter-agency learning about pilot programs (2019). https://doi.org/10.7922/G2QR4VBR.

Qualtrics.28 QUESTIONS TO HELP RESEARCH BUYERS OF ONLINE SAMPLES. (2014). https:// success.qualtrics.com/rs/qualtrics/images/ESOMAR\%2028\%202014.pdf.

Rayle, L., Dai, D., Chan, N., Cervero, R., Shaheen, S.: Just a better taxi? A survey-based comparison of taxis, transit, and ridesourcing services in San Francisco. Transp. Policy 45(January), 168-178 (2016). https://doi.org/10.1016/j.tranpol.2015.10.004

Sarrias, Mauricio, Ricardo Daziano. Multinomial logit models with continuous and discrete individual heterogeneity in R: The Gmnl Package. J. Stat. Softw. 79(1), 1-46. https://doi.org/10.18637/jss.v079.i02.

Schaller, Bruce. The New Automobility: Lyft, Uber and the Future of American Cities." Brooklyn, NY: Schaller Consulting (2018). http://www.schallerconsult.com/rideservices/automobility.pdf.

Smith, Aaron. Shared, collaborative and on demand: The New Digital Economy.” May 19, 2016 (2016). http://www.pewinternet.org/2016/05/19/the-new-digital-economy/.

Southeastern Pennsylvania Transportation Authority. SEP-TAINABLE Annual Report. Southeastern Pennsylvania Transit Authority (2019). http://www.septa.org/sustain/pdf/2019-03-septainable-report.pdf.

Taylor, Brian D., Hiroyuki Iseki, Mark A. Miller, Michael Smart. Thinking outside the bus: Understanding user perceptions of waiting and transferring in order to increase transit use. PATH Research Report (2009). https://trid.trb.org/view/886713.

Tirachini, A.: Ride-hailing, travel behaviour and sustainable mobility: An international review. Transportation 47(4), 2011-2047 (2020). https://doi.org/10.1007/s11116-019-10070-2

NYC Taxi \& Limousine Commission. n.d. "TLC Data Hub.” https://tlcanalytics.shinyapps.io/tlc_dash/. Accessed 9 Jan 2021.

Train, Kenneth E. Discrete choice methods with simulation, 2 edition. Cambridge; New York: Cambridge University Press (2009).

U. S. Census Bureau. 2019. "U.S. Census Bureau QuickFacts.” July 2019. https://www.census.gov/quick facts/fact/table/bostoncitymassachusetts,US/PST045219.

U. S. Census Bureau.. n.d. 2019 American Community Survey 1-Year Estimates. Accessed January 9, 2021. https://data.census.gov/cedsci/.

Wang, H., Yang, H.: Ridesourcing systems: A framework and review. Transp. Res. B Methodological 129(November), 122-155 (2019). https://doi.org/10.1016/j.trb.2019.07.009

Ward, J.W., Michalek, J.J., Samaras, C., Azevedo, I.L., Henao, A., Rames, C., Wenzel, T.: The impact of Uber and Lyft on vehicle ownership, fuel economy, and transit across U.S. cities. Iscience 24(1), 101933 (2021). https://doi.org/10.1016/j.isci.2020.101933

Yang, L., Choudhury, C., Ben-Akiva, M., Abreu, J., Carvalho, D., Carvalho, S. Stated preference survey for new smart transport modes and services. (2009). https://its.mit.edu/sites/default/files/documents/wp_ trsys_2009_mar_lyang_et_al\%282\%29.pdf

Publisher's Note Springer Nature remains neutral with regard to jurisdictional claims in published maps and institutional affiliations. 
Xiaoxia Dong, Ph.D., is research associate in the Department of City and Regional Planning in the University of Pennsylvania Stuart Weitzman School of Design.

Erick Guerra, Ph.D., is associate professor in the Department of City and Regional Planning in the University of Pennsylvania Stuart Weitzman School of Design.

Ricardo A. Daziano, Ph.D., is associate professor in Civil and Environmental Engineering at Cornell University. 